\title{
Considerations for nasal bone fractures: Preoperative, perioperative, and postoperative
}

\author{
Dong Gil Han \\ Department of Plastic and \\ Reconstructive Surgery, Daegu Catholic \\ University School of Medicine, Daegu, \\ Korea
}

\begin{abstract}
Nowadays, the incidence of nasal bone fracture is increasing because of social complexity with frequent social activity, and reduction of fractures is relatively simple and can be corrected in short operation time. However, the postoperative results are known to be less satisfied with higher complication rates relatively. These problems could have resulted from inaccurate recognition and interpretation of fracture aspect, inaccurate planning of operation resulting in under or overcorrection, ignoring septal management, complication related nasal packings with removal, postoperative management, and patient satisfaction with complication.
\end{abstract}

Keywords: Bone / Closed fracture reduction / Fractures / Nasal bone

\section{INTRODUCTION}

In recent years, the incidence of nasal bone fractures has increased concomitantly with increasing social complexity and a greater frequency of sports activities. Although fracture reduction is relatively simple, and most fractures can be corrected in a short surgical procedure, the postoperative results of the surgical correction of nasal bone fractures tend to be relatively unsatisfactory, with complication rates that are higher than desired [1-4].

These problems result from several issues, including inaccurate recognition and interpretation of various aspects of fractures; inaccurate surgical planning, which results in undercorrection or overcorrection; failure to perform proper management of the septum; complications related to nasal packing and its removal; postoperative management; and patients' level of satisfaction in light of potential complications. In this review, we discuss preoperative, perioperative, and postoperative considerations that surgeons should keep in mind to optimize the outcomes of nasal bone fracture correction.

\section{Correspondence: Dong Gil Han}

Department of Plastic and Reconstructive Surgery, Daegu Catholic University

School of Medicine, 33 Duryugongwon-ro 17-gil, Nam-gu, Daegu 42472, Korea E-mail: dghan1001@cu.ac.kr

Received January 16, 2020 / Revised January 31, 2020 / Accepted February 11, 2020

\section{PREOPERATIVE CONSIDERATIONS}

Preoperatively, clinicians should meticulously interpret both two-dimensional and three-dimensional imaging in order to properly recognize and interpret clinically relevant aspects of the fracture. According to Park et al. [5], it is sometimes difficult to diagnose nasal bone fractures through simple X-rays, which showed a sensitivity of $62 \%$ for diagnosing nasal bone fractures. In the report of Min et al. [6], the sensitivity of simple X-rays was $71.9 \%$ in children and $80.9 \%$ in adults. Kim and Hwang [7] reported that the sensitivity and specificity of computed tomography (CT) readings were $95.0 \%$ and $92.9 \%$, respectively. The positive predictive value of CT readings was 99.3\%. In $17.1 \%$ of cases, a reading of "nasal bone fracture" did not clinically correspond to a nasal bone fracture, while readings of "no nasal bone fracture" or "old nasal bone fracture" clinically corresponded to a nasal bone fracture in $3.3 \%$ of cases. In addition, three-dimensional imaging may be inferior to simple radiography or CT in determining the presence of a fracture, but if a clear and sharp fracture line is present, threedimensional imaging has been reported to be useful for determining the extent of the fracture, the extent of the depression, and the degree of deviation or displacement [8]. Additionally, Han et al. [9] reported that fracture patterns predicted by resi- 
dents and plastic surgeons based on simple radiography and two-dimensional CT images were very different from the actual characteristics of nasal bone fractures according to three-dimensional CT scans. Therefore, it is necessary to obtain more accurate information on fracture status, including the range of the fracture, the degree of deflection or displacement, and the overall characteristics of the fracture through three-dimensional imaging.

\section{PERIOPERATIVE CONSIDERATIONS}

\section{Precise surgical plan and optimal reduction}

When operating on a fracture, even if the case appears to be routine, it is necessary to create a precise surgical plan to avoid undercorrection or overcorrection, to minimize iatrogenic damage, and to reduce the operating time by minimizing the information that must be obtained from three-dimensional imaging. It is preferable to perform dorsal pyramidal reduction first, in order to secure space for restoring fractured segments of the lateral nasal wall and the frontal process of the maxilla to their anatomical positions. Then, reduction of depressed lateral nasal walls, the frontal process, and/or outward-deviated lateral nasal walls can be done.

\section{Nasal septum management}

After completing bony reduction, it may be easy to overlook management of the septum; however, it is difficult to obtain excellent results without addressing septal problems.

The author usually manipulates areas of septal deviation with a long nasal speculum and a No. 3 knife handle wrapped with a Vaseline gauze, by pushing the septum from the convex side to the concave side and ensuring that the septal line is as straight as possible.

\section{Retouching areas of bony reduction}

After manipulating areas of septal deviation and confirming the alignment of the bony reduction with its the anatomical position, it is preferable to perform additional bony reduction following the initial sequence of reduction, because when inserting a long nasal speculum and spreading it out in the nasal cavity, manipulation of the septum with a knife handle may disturb the alignment of the nasal pyramid, which contains fractured segments that have already been reduced.

\section{Nasal packing and securing the nasal airway}

After reduction, a roll of Vaseline gauze is packed in the dorsal nasal cavity (only on the side that was depressed preoperatively) to support the reduced bone fragments. Merocel packs can be placed in both nasal airways. Before finishing the operation, it is necessary to ensure the absence of an excessive amount of blood clots in the throat or ongoing posterior nasal bleeding. In most cases, many blood clots are present in the throat after reduction of a nasal bone fracture, so the author removes them using a mouth gag and suction immediately, and then checks whether there is ongoing posterior nasal bleeding. If nasal bleeding is present, wet gauze is packed in the posterior nasal airway and nasal tip compression is performed repeatedly until the bleeding stops, as confirmed visually. After verifying that nasal bleeding has stopped, the author finishes the operation after applying an external nasal thermo-splint.

\section{POSTOPERATIVE CONSIDERATIONS}

\section{Timing of packing removal}

Closed reduction with nasal packing for 3 to 7 days is the usual procedure for managing a nasal bone fracture. Most patients experience severe discomfort because nasal breathing is impossible $[10,11]$. Many reports have investigated ways to reduce patients' discomfort and complications, but the general consensus is that the appropriate duration of nasal packing is 3 to 7 days [11-14]. However, in a previous study of the effect of early removal of nasal packing, the author analyzed 92 cases in which Merocel packs were removed 6 hours after the operation and the packed rolls of Vaseline gauze were removed 1 day after the operation to increase patients' comfort. No significant difference in outcomes was found, and 1 day after the operation (after the nasal filling had been removed), most of the patients had no complaints of discomfort, with the exception of five with headache, one with nausea, and two with generalized discomfort (Fig. 1) [15]. Another previous study reported that reduced nasal segments tended to undergo progressive remodeling; furthermore, postoperative outcomes continued to improve over the first month postoperatively despite the early removal of nasal packings, and early packing removal contributed to an increase in patient satisfaction by reducing discomfort [16].

\section{Patient satisfaction}

Several studies have reported the results of nasal bone fracture reduction in terms of patient satisfaction and/or the complication rate [1-3,17]. However, patient satisfaction is subjective and is limited to an evaluation of the results of the operation and the factors that influenced the results. Additionally, in some cases, patients were not satisfied with the results of the procedure even though there were no problems as evaluated by the clinician subjectively and by CT scans objectively. Nevertheless, the 
author reported that outcomes assessed on CT scans were correlated with overall patient satisfaction, and suggested that it is preferable to evaluate the correlations between subjective and objective postoperative results using both $\mathrm{CT}$ images and patient satisfaction [18].

\section{Complications}

Lee et al. [4] reported the complication rates of different types of fractures in the Stranc and Robertson classification, and found that fractures caused by lateral impacts resulted in more nasal deformities than those caused by frontal impacts. Sam et al. [19] investigated the association between septal deviation of the nose and external nasal deformities. Murray [20] reported that cartilaginous bending of the septum led to long-term nasal deviation after a nasal manipulation that initially appeared satisfactory.

In a previous study, the author reported that the complication rates of fractures belonging to types FI, LII, and C were statisti-

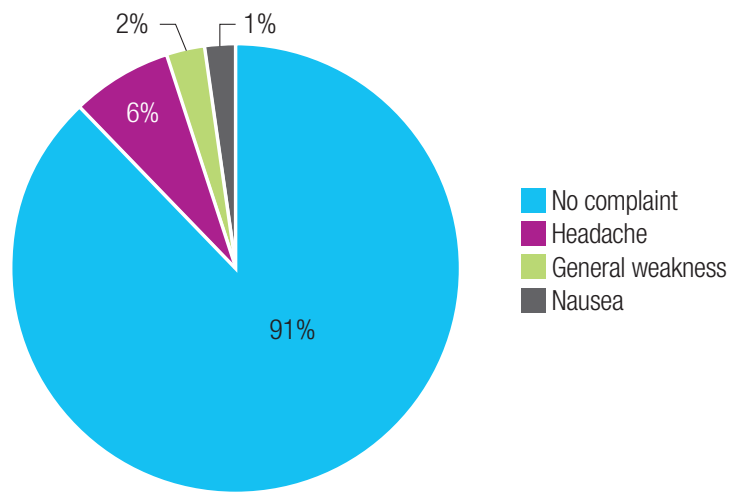

Fig. 1. Patients' complaints at 1 day after the operation. Reprinted from Han et al. Arch Craniofac Surg 2012;13:119-24 [15]. cally significantly higher than those of fractures categorized as FII and LI (FI, frontal impact group type I; FII, frontal impact group type II; LI, lateral impact group type I; LII, lateral impact group type II; C, comminuted fracture group). However, there were no statistically significant differences in the complication rates between the FII and LI groups, or between the FI, LII, and C groups (Table 1). Additionally, no statistically significant differences were found in the incidence of complications according to the presence or absence of septal fracture or deviation for each fracture type. However, the $p$-value for the difference in the total group was 0.046 , corresponding to a statistically significant difference in the complication rate according to the presence of septal fracture or deviation in the total group of nasal bone fractures (Table 2) [18].

\section{CONCLUSION}

The goal of treatment of nasal bone fractures is to restore the

Table 2. Comparison of the complication rate according to the presence of a septal fracture

\begin{tabular}{llcl}
\hline \multirow{2}{*}{ Fracture type } & \multicolumn{2}{c}{ Septal fracture } & $p$-value ${ }^{\mathrm{a})}$ \\
\cline { 2 - 3 } & \multicolumn{1}{c}{-} & + & \\
\hline $\mathrm{FI}$ & $2(5.13)$ & $4(8.89)$ & 0.504 \\
$\mathrm{FII}$ & 0 & $1(4.76)$ & 0.656 \\
LI & $2(3.39)$ & $2(5.56)$ & 0.610 \\
LII & $1(8.33)$ & $11(14.86)$ & 0.545 \\
C & 0 & $3(15.00)$ & 0.472 \\
Total & $5(4.27)$ & $21(10.71)$ & 0.046 \\
\hline
\end{tabular}

Values are presented as number (\%).

Fl, frontal impact group type I; FIl, frontal impact group type II; LI, lateral impact group type I; LII, lateral impact group type II; C, comminuted fracture group.

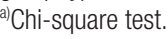

Reprinted from Kang et al. Arch Craniofac Surg 2017;18:25-9 [18].

Table 1. Complications of nasal bone fractures

\begin{tabular}{|c|c|c|c|c|c|c|c|c|c|c|c|c|}
\hline \multirow{2}{*}{ Complications } & \multicolumn{2}{|c|}{$\mathrm{FI}$} & \multicolumn{2}{|c|}{ FII } & \multicolumn{2}{|c|}{$\mathrm{LI}$} & \multicolumn{2}{|c|}{ LII } & \multicolumn{2}{|c|}{ C } & \multirow{2}{*}{ Total } & \multirow{2}{*}{$p$-value $e^{a)}$} \\
\hline & - & + & - & + & - & + & - & + & - & + & & \\
\hline Hump nose & 0 & 1 & 0 & 0 & 0 & 0 & 0 & 2 & 0 & 0 & 3 & \\
\hline Saddle nose & 1 & 2 & 0 & 0 & 1 & 0 & 0 & 0 & 0 & 0 & 4 & \\
\hline Nasal widening & 0 & 1 & 0 & 0 & 0 & 2 & 0 & 0 & 0 & 0 & 3 & \\
\hline Deviated nose & 1 & 0 & 0 & 0 & 1 & 0 & 1 & 6 & 0 & 3 & 12 & \\
\hline Nasal airway obstruction & 0 & 0 & 0 & 1 & 0 & 0 & 0 & 1 & 0 & 0 & 2 & \\
\hline Hyposmia & 0 & 0 & 0 & 0 & 0 & 0 & 0 & 2 & 0 & 0 & 2 & \\
\hline Total & 2 & 4 & 0 & 1 & 2 & 2 & 1 & 11 & 0 & 3 & 26 & \\
\hline Complication rate & \multicolumn{2}{|c|}{$6(7.14)$} & \multicolumn{2}{|c|}{$1(4.00)$} & \multicolumn{2}{|c|}{$4(4.21)$} & \multicolumn{2}{|c|}{12 (13.95) } & \multicolumn{2}{|c|}{$3(13.04)$} & $26(8.31)$ & $<0.001^{\text {b) }}$ \\
\hline
\end{tabular}

Values are presented as number or number (\%).

$\mathrm{Fl}$, frontal impact group type I; Fll, frontal impact group type II; LI, lateral impact group type I; LII, lateral impact group type II; C, comminuted fracture group.

Scheffe multiple comparison result: $\mathrm{Fll}, \mathrm{LI}<\mathrm{Fl}, \mathrm{LII}, \mathrm{C}$. a) One-way analysis of variance; ${ }^{b}$ Complication rate by fracture type.

Reprinted from Kang et al. Arch Craniofac Surg 2017;18:25-9 [18]. 
nose-in terms of both appearance and function-to its pretrauma state. Therefore, to obtain more favorable surgical results, several preoperative, perioperative, and postoperative considerations should be kept in mind.

\section{NOTES}

\section{Conflict of interest}

No potential conflict of interest relevant to this article was reported.

\section{ORCID}

Dong Gil Han https://orcid.org/0000-0001-7922-5859

\section{REFERENCES}

1. Yilmaz MS, Guven M, Varli AF. Nasal fractures: is closed reduction satisfying? J Craniofac Surg 2013;24:e36-8.

2. Chung SH, Park J, Choe J, Baek SM. Clinical analysis of satisfaction of nasal bone reduction. J Korean Soc Plast Reconstr Surg 1994;21:984-90.

3. Hong SB, Choi BW, Suh IS, Ha JH. Clinical \& radiological evaluation of the nasal bone fractures. J Korean Soc Plast Reconstr Surg 1996;23:1572-82.

4. Lee JH, Park WY, Nam HJ, Kim YH. Complications of the nasal bone fractures according to the stranc classification. J Korean Cleft Palate-Craniofac Assoc 2008;9:62-6.

5. Park CS, Suh CH, Seok EH, Chung WK, Byun US. Nasal bone fractures: evaluation with thin-section CP. J Korean Radiol Soc 1995;33:197-203.

6. Min KH, Hong SH, Lee JH. The value of facial bone CAT scan in the diagnosis of the nasal bone fracture. J Korean Soc Plast Reconstr Surg 2006;33:440-4.

7. Kim DH, Hwang K. Discordance between clinical diagnosis and reading of computerized tomography in nasal bone fracture. J Korean Soc Plast Reconstr Surg 2010;37:375-9.

8. Kwak JH, Han JK, Koh KS, Yang KH. Three-dimensional ref- ormation of computed tomography in the nasal bone fractures. J Korean Radiol Soc 1989;25:469-75.

9. Han DG, Kim TS, Park DD, Shim JS, Lee YJ. The accuracy rate in comprehension of aspects of nasal bone fracture based on simple X-ray and 2D CT compared with 3D image. Arch Craniofac Surg 2012;13:111-8.

10. Min BY, Kim HU, Chu HR, Park CH. A comparative study between $\mathrm{K}$-wire and intranasal packing in nasal bone fracture. Korean J Otolaryngol-Head Neck Surg 2002;45:1073-6.

11. Lim EJ, Song SH, Kim JS. Comparison of nasal packing and septal suturing following septoplasty. Korean J OtolaryngolHead Neck Surg 2006;49:904-7.

12. Jung YJ, Choi YW, Nam SH, Yoon GY. The usefulness of airway tube $\operatorname{Merocel}(\mathrm{R})$ on treatment of nasal bone fracture. J Korean Cleft Palate-Craniofac Assoc 2009;10:14-8.

13. Kong JS, Jung JA, Kang SR, Kim YW, Jeon YW. Fixation of nasal bone fracture with carved $\operatorname{Merocel}(\mathrm{R})$. J Korean Cleft Palate-Craniofac Assoc 2011;12:93-6.

14. Kim JY, Kim YH. The usefulness of a bronchodilator after the closed reduction of nasal bone fracture. J Korean Cleft PalateCraniofac Assoc 2011;12:22-7.

15. Han DG, Kim TS. The effect of half day nasal packing in results of closed reduction of nasal bone fracture. Arch Craniofac Surg 2012;13:119-24.

16. Lee BM, Han DG. Acute bone remodeling after reduction of nasal bone fracture on computed tomography imaging. Arch Craniofac Surg 2014;15:63-9.

17. Love RL. Nasal fractures: patient satisfaction following closed reduction. N Z Med J 2010;123:45-8.

18. Kang CM, Han DG. Correlation between operation result and patient satisfaction of nasal bone fracture. Arch Craniofac Surg 2017;18:25-9.

19. Sam A, Deshmukh PT, Patil C, Jain S, Patil R. Nasal septal deviation and external nasal deformity: a correlative study of 100 cases. Indian J Otolaryngol Head Neck Surg 2012;64:312-8.

20. Murray JA. Management of septal deviation with nasal fractures. Facial Plast Surg 1989;6:88-94. 